\title{
Alpha-Asarone Protects Endothelial Cells from Injury by Angiotensin II
}

\author{
Hai-Xia Shi, ${ }^{1,2}$ Jiajun Yang, ${ }^{3}$ Tao Yang, ${ }^{4}$ Yong-Liang Xue, ${ }^{2}$ Jun Liu, ${ }^{2}$ Ya-Juan Li, \\ Dan-Dan Zhang, ${ }^{2}$ Jin-Wen $\mathrm{Xu}^{2}$, and Ka Bian ${ }^{5}$ \\ ${ }^{1}$ Department of Traditional Chinese Medicine, Third People's Hospital Affiliated to Shanghai Jiao Tong University School of Medicine, \\ 280 Mohe Road, Shanghai 201999, China \\ ${ }^{2}$ Murad Research Center for Modernization Chinese Medicine, Shanghai University of Traditional Chinese Medicine, \\ 1200 Cailun Road, Shanghai 201203, China \\ ${ }^{3}$ Department of Neurology, Sixth People's Hospital Affiliated to Shanghai Jiao Tong University, 600 Yishan Road, \\ Shanghai 200233, China \\ ${ }^{4}$ Institute of Liver Diseases, Shuguang Hospital Affiliated to Shanghai University of Traditional Chinese Medicine, \\ Zhangheng Road, Zhangjiang Hi-Tech Park, Shanghai 201210, China \\ ${ }^{5}$ Department of Biochemistry and Molecular Biology, George Washington University, 2300 I Street, Ross Hall 543, \\ Washington, DC 20037, USA
}

Correspondence should be addressed to Jiajun Yang; yangjiajunsci@163.com and Ka Bian; bcmkxb@gwu.edu

Received 9 December 2013; Revised 25 January 2014; Accepted 4 February 2014; Published 18 March 2014

Academic Editor: Michał Tomczyk

Copyright (C) 2014 Hai-Xia Shi et al. This is an open access article distributed under the Creative Commons Attribution License, which permits unrestricted use, distribution, and reproduction in any medium, provided the original work is properly cited.

$\alpha$-Asarone is the major therapeutical constituent of Acorus tatarinowii Schott. In this study, the potential protective effects of $\alpha$ asarone against endothelial cell injury induced by angiotensin II were investigated in vitro. The EA.hy926 cell line derived from human umbilical vein endothelial cells was pretreated with $\alpha$-asarone $(10,50,100 \mu \mathrm{mol} / \mathrm{L})$ for $1 \mathrm{~h}$, followed by coincubation with Ang II $(0.1 \mu \mathrm{mol} / \mathrm{L})$ for $24 \mathrm{~h}$. Intracellular nitric oxide (NO) and reactive oxygen species (ROS) were detected by fluorescent dyes, and phosphorylation of endothelial nitric oxide synthase (eNOS) at $\operatorname{Ser}^{1177}$ was determined by Western blotting. $\alpha$-Asarone dose-dependently mitigated the Ang II-induced intracellular NO reduction $(P<0.01$ versus model) and ROS production $\left(P<0.01\right.$ versus model). Furthermore, eNOS phosphorylation $\left(\operatorname{Ser}^{1177}\right)$ by acetylcholine was significantly inhibited by Ang II, while pretreatment for $1 \mathrm{~h}$ with $\alpha$-asarone partially prevented this effect $(P<0.05$ versus model $)$. Additionally, cell viability determined by the MTT [3-(4,5-dimethylthiazol-2-yl)-2,5-diphenyltetrazolium bromide] assay (105 114.5\% versus control, $P>0.05)$ was not affected after $24 \mathrm{~h}$ of incubation with $\alpha$-asarone at 1-100 $\mu \mathrm{mol} / \mathrm{L}$. Therefore, $\alpha$-asarone protects against Ang II-mediated damage of endothelial cells and may be developed to prevent injury to cardiovascular tissues.

\section{Introduction}

Endothelial cells play key roles in maintaining homeostasis of blood vessels, such as by regulating the vascular tone; inhibiting the proliferation of smooth muscle cells; and preventing inflammation, platelet aggregation, and coagulation [1]. However, reduction in bioavailable nitric oxide (NO) and excess production of reactive oxygen species (ROS) are important contributors to endothelial cell dysfunction, which is the initial factor in development of vascular diseases. It has been suggested that the increase of angiotensin II (Ang II) level in the blood causes endothelial cell dysfunction during the pathogenesis of such conditions as atherosclerosis (AS) and hypertension. The underlying mechanisms involve the following: an increase in permeability of vascular endothelial cells or intima, which contributes to lipid deposition and invasion of harmful substances; activation of $\mathrm{NF}-\kappa \mathrm{B}$, thereby promoting the endothelial cells to express monocyte chemotactic protein-1 (MCP-1), soluble intercellular adhesion molecule-1 (sICAM-1), and interleukin-6 
(IL-6), which aggravate inflammatory reactions; activation of the reduced form of nicotinamide-adenine dinucleotide $(\mathrm{NADH})$ and reduced nicotinamide adenine dinucleotide phosphate (NADPH) oxidase of the cell membrane, leading to oxidative stress; and expression of vasoactive substances and even apoptosis of endothelial cells [2]. Additionally, a large number of studies have shown that Ang II induces endothelial nitric oxide synthase (eNOS) uncoupling through the activation of NADPH oxidase, reducing the content of $\mathrm{BH}_{4}$, and contributes to the reduction of $\mathrm{NO}$, eventually resulting in increased ROS and endothelial cell dysfunction [3]. Ang II at $0.1 \mu \mathrm{mol} / \mathrm{L}$ has been shown to inhibit the phosphorylation of eNOS at Ser ${ }^{1177}$ and the production of NO stimulated by insulin in human vascular endothelial cells (HUVECs) [4]. Furthermore, Ang II can also upregulate the phosphorylation of eNOS at $\mathrm{Tyr}^{657}$, thereby inhibiting its activity, decreasing the production of NO, and mediating functional damage of endothelial cells [5].

As the principle active component of the medicinal plant of Acorus tatarinouii Schott, $\alpha$-asarone (2,4,5-trimethoxy-1propenyl benzene) exhibits pharmacological activities that mirror those of the whole plant extract. It harbors antiasthma [6], antiepilepsy [7], and cardiovascular protective $[8,9]$ properties, as well as the ability to lower lipemia and cholesteremia [10]. Recent studies have attributed the neuroprotective $[11,12]$ and antiepileptic [13] effects of $\alpha$ asarone to its antioxidant properties [14]. Despite reports of its hypolipidemic [15, 16] and antiplatelet [17] effects, the potential protective activities of $\alpha$-asarone on vascular endothelial cells have not yet been determined.

Our previous study showed that $\alpha$-asarone possessed a endothelium-dependent vasodilation property, and in normal HUVEC-derived EA.hy926 cells, $\alpha$-asarone has been shown to upregulate the expression of phosphorylated eNOS $\left(\operatorname{Ser}^{1177}\right)$, causing an increase in the production of NO. In the present study, the protective effects of $\alpha$-asarone against endothelial dysfunction induced by Ang II and the underlying molecular mechanisms were investigated. The results showed effective bioactivities of $\alpha$-asarone in improving the Ang II-mediated reduction in NO and ROS production in endothelial cells in a dose-dependent manner. Furthermore, the inhibition of acetylcholine (ACh)-mediated phosphorylation of eNOS Ser ${ }^{1177}$ induced by Ang II could be partially reversed by pretreatment with $\alpha$-asarone at doses which did not influence cellular proliferation.

\section{Materials and Methods}

2.1. Chemicals. All chemicals used in this study were purchased from Sigma (St Louis, MO, USA) unless otherwise specified. The stock solution of $\alpha$-asarone $\left(10^{5} \mu \mathrm{mol} / \mathrm{L}\right)$ was dissolved in dimethyl sulfoxide (DMSO) and then diluted in culture medium to a working concentration. Ang II and ACh were prepared in distilled water.

2.2. Cells. The EA.hy926 cell line was purchased from American Type Culture Collection (ATCC, Manassas, VA, USA, CRL-2922) and cultured in $10 \mathrm{~cm}$ diameter Petri dishes with
Dulbecco's Modified Eagle Medium (DMEM) containing $10 \%$ fetal calf serum (FCS) and supplemented with $1 \%$ hypoxanthine-aminopterin-thymidine based on the manufacturer's recommendations. The cells were incubated at $37^{\circ} \mathrm{C}$ in humidified air containing $5 \% \mathrm{CO}_{2}$. The 4 th to 8 th generations of cells were used in the experiments.

\subsection{Determining Effects of Ang II on Intracellular ROS/NO} Levels. EA.hy926 cells were subcultured at 50,000/well in 96well plates. Before the experiment, the medium was changed to serum-free and phenol red-free RPMI 1640 medium and cultured overnight $(8 \sim 10 \mathrm{~h})$ at $37^{\circ} \mathrm{C}$ with $5 \% \mathrm{CO}_{2}$. The model group was cultured with phenol red-free RPMI 1640 medium containing Ang II at a final concentration of $0.1 \mu \mathrm{mol} / \mathrm{L}$, while the control group was cultured with the same medium without Ang II. Both groups were cultivated for $24 \mathrm{~h}$. As a positive control, the NO synthesis inhibitor L-NG-nitro arginine methyl ester (L-NAME) at the final concentration of $100 \mu \mathrm{mol} / \mathrm{L}$ was used to treat EA.hy926 cells for $1 \mathrm{~h}$ before detection of NO and ROS levels. Dihydroethidium (DHE, final concentration $2 \mu \mathrm{mol} / \mathrm{L}$ ) and difluorofluorescein diacetate (DAF-FM DA, final concentration $5 \mu \mathrm{mol} / \mathrm{L}$ ) diluted with serum-free and phenol red-free RPMI1640 medium were loaded into the cells by incubation in the dark for $30 \mathrm{~min}$ at $37^{\circ} \mathrm{C}$ before detection. The supernatant was discarded, and the cells were washed with phosphate buffer saline (PBS) 2-3 times before adding $200 \mu \mathrm{L}$ of PBS for fluorescence detection using a full wavelength multifunctional microplate reader. For NO detection, ACh was added at the final concentration of $10 \mu \mathrm{mol} / \mathrm{L}$ and incubated for 10 30 min before detection.

\subsection{Determining Protective Effect of $\alpha$-Asarone against Ang II-} Mediated Injury of Endothelial Cells by Measuring ROS/NO Content. EA.hy926 cells were subcultured at 50,000/well in 96-well plates as in the experiment above and pretreated with $\alpha$-asarone at different concentrations $(10,50$, and $100 \mu \mathrm{mol} / \mathrm{L})$ for $1 \mathrm{~h}$. Subsequently, Ang II $(0.1 \mu \mathrm{mol} / \mathrm{L})$ was added to the cultures and incubated for $24 \mathrm{~h}$ at $37^{\circ} \mathrm{C}$. Thereafter, the cells were loaded with the fluorescent probes for $30 \mathrm{~min}$, and then the extracellular residual dyes were washed away before detection as described above.

2.5. Determining Protective Effects of $\alpha$-Asarone against Ang II-Mediated Injury of Endothelial Cells by Detection of AChInduced eNOS Ser ${ }^{117}$ Phosphorylation. EA.hy926 cells were seeded in $10 \mathrm{~cm}$ Petri dishes at $1 \times 10^{6} / \mathrm{dish}$. When the cells had grown to $90 \%$ confluency, they were preincubated in serum-free DMEM with $\alpha$-asarone $(10 \mu \mathrm{mol} / \mathrm{L})$ for $1 \mathrm{~h}$ and then treated with Ang II at $0.1 \mu \mathrm{mol} / \mathrm{L}$ for $24 \mathrm{~h}$. The control group was incubated in serum-free DMEM. After the incubation, the medium of the treated group was switched to DMEM with ACh at $10 \mu \mathrm{mol} / \mathrm{L}$, and then cells were incubated for $0,2,5,10,15,30$, and $60 \mathrm{~min}$. Total cellular proteins were extracted for Western blot analysis of total eNOS and phosphorylated eNOS $\left(\operatorname{Ser}^{1177}\right)$. The cell culture dish was placed in ice and the cells was washed with ice-cold PBS; after aspirating the PBS, add ice-cold lysis buffer and scrape adherent cells off the dish using a cold plastic cell scraper; 
then, gently transfer the cell suspension into a precooled microcentrifuge tube. After that, maintain constant agitation for 30 minutes at $4^{\circ} \mathrm{C}$, spin at $16,000 \times \mathrm{g}$ for 20 minutes in a $4^{\circ} \mathrm{C}$ precooled centrifuge, transfer the supernatant to a fresh tube kept on ice, and discard the pellet. Remove a small volume $(20 \mu \mathrm{L})$ of lysate to perform a protein assay and add an equal volume of $2 x$ Laemmli sample buffer. Then load and run the gel from 1 to 2 hours at $100 \mathrm{~V}$, before transferring the protein from the gel to the membrane; after that, block the membrane for 1 hour at room temperature using 5\% blocking solution and incubate membrane with appropriate dilutions of primary antibody in 5\% blocking solution overnight at $4^{\circ} \mathrm{C}$. Then, wash the membrane in three washes of TBST, 5 minutes each. Incubate the membrane with the recommended dilution of labeled secondary antibody in $5 \%$ blocking buffer in TBST at room temperature for 1 hour. Then, wash the membrane in three washes of TBST, 5 minutes each. To acquire images, use darkroom development techniques for chemiluminescence. Quantity 1 software (BioRad Laboratories, Inc. USA) was used for immunoblot analysis.

2.6. MTT [3-(4,5-Dimethylthiazol-2-yl)-2,5-diphenyltetrazolium bromide] Cell Viability Assay for Determination of Drug Safety. EA.hy926 cells were subcultured at 5,000/well in 96well plates and switched to serum-free DMEM overnight (8 $10 \mathrm{~h}$ ) before the experiment when $\alpha$-asarone was added at different concentrations $(1,5,10,50$, and $100 \mu \mathrm{mol} / \mathrm{L})$ and incubated for $24 \mathrm{~h}$. The cell viability assay was conducted by adding $20 \mu \mathrm{L}$ of working MTT solution per well and incubating for $4 \mathrm{~h}$ at $37^{\circ} \mathrm{C}$ in $5 \% \mathrm{CO}_{2}$. After discarding the supernatant, $150 \mu \mathrm{L}$ of DMSO was added per well, mixed in a microplate reader, and reacted for $10 \mathrm{~min}$ at room temperature. The absorbance was detected at $570 \mathrm{~nm}$ to calculate the cell viability.

2.7. Statistical Analysis. Values were expressed as means \pm standard deviation (SD). Statistical significance of results between different groups was calculated using one-way analysis of variance (ANOVA). All data analyses were performed with SPSS v15.0 (SPSS, Chicago, USA). A $P$ value of $<0.05$ was considered significant.

\section{Results}

3.1. Ang II Increases ROS and Decreases NO in EA.hy926 Cells. As shown in Figure 1, after incubation with Ang II $(0.1 \mu \mathrm{mol} / \mathrm{L})$ for $24 \mathrm{~h}$, the intracellular ROS level statistically and significantly increased by $34 \%$ when compared with control group $(P<0.05)$. In the group pretreated with the NO synthesis inhibitor L-NAME before exposure to Ang II, the ROS level was decreased $(P<0.05)$ compared with the model (Ang II only) group, suggesting that the elevation of ROS by Ang II was due to eNOS uncoupling. Meanwhile, the NO level in the model group decreased by $11 \%$ when compared with control group, and this difference was statistically significant $(P<0.01)$. These results indicated that the model was constructed successfully (Figure 1).

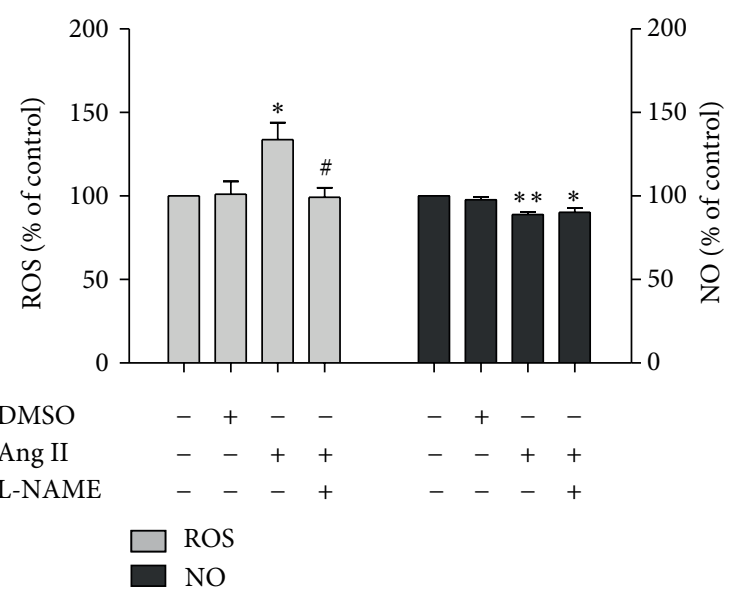

FIgURE 1: ROS/NO levels in EA.hy926 cells induced by Ang II. Cells were treated with Ang II at $0.1 \mu \mathrm{mol} / \mathrm{L}$ for $24 \mathrm{~h}$. The intracellular ROS and NO levels were detected with the permeable fluorescent dyes DHE and DAF-FM DA, respectively. DMSO was used as the solvent control at the concentration of $1 \%$. L-NAME $(100 \mu \mathrm{mol} / \mathrm{L})$ was used to sustain the changes of ROS and NO related to eNOS. Data are expressed as means \pm SD from three independent experiments. ${ }^{*} P<0.05$ versus control; ${ }^{* *} P<0.01$ versus control; ${ }^{\#} P<0.05$ versus model.

3.2. $\alpha$-Asarone Protects against Injury to Endothelial Cells by Attenuating Ang II-Mediated Changes in Intracellular ROS/NO. Pretreatment of EA.hy926 cells with $\alpha$-asarone at concentrations of 10,50 , or $100 \mu \mathrm{mol} / \mathrm{L}$ could significantly inhibit the intracellular ROS levels induced by Ang II, while at the same time it also minimized the decrease of intracellular NO levels induced by Ang II (Figure 2). These results suggested that $\alpha$-asarone may have protective effects against oxidative stress injury of endothelial cells induced by Ang II.

3.3. $\alpha$-Asarone Reverses Ang II-Mediated Inhibition of AChInduced Phosphorylation of eNOS ( $\left.\mathrm{Ser}^{1177}\right)$. The ability of the eNOS agonist ACh $(10 \mu \mathrm{mol} / \mathrm{L})$ to upregulate phosphorylation of eNOS at the Ser ${ }^{1177}$ site was confirmed, the effect of which was exhibited as twin peaks (Figure 3, control). The level of eNOS Ser ${ }^{1177}$ phosphorylation increased significantly after 2 min of ACh treatment and then dropped sharply; thereafter, it increased slowly, reaching the second peak at $30 \mathrm{~min}$ and achieving a level which was 5.5 times higher than that of the control group $(0 \mathrm{~min})(P<0.01)$ (Figure 3 , Control).

Meanwhile, treatment of the EA.hy926 cells with Ang II $(0.1 \mu \mathrm{mol} / \mathrm{L})$ for $24 \mathrm{~h}$ before stimulation with ACh $(10 \mu \mathrm{mol} / \mathrm{L})$ for $0-60 \mathrm{~min}$ had a profound effect on the ACh-mediated induction of eNOS Ser ${ }^{1177}$ phosphorylation (Figure 3, Model). While there was no significant change in total eNOS protein, the eNOS Ser ${ }^{117}$ phosphorylated protein level initially induced by ACh was minimal, disappearing over time, and the difference was statistically significant compared with the control group. However, when the EA.hy926 cells were pretreated with $\alpha$-asarone $(10 \mu \mathrm{mol} / \mathrm{L})$ for $1 \mathrm{~h}$, followed by incubation with Ang II $(0.1 \mu \mathrm{mol} / \mathrm{L})$ for $24 \mathrm{~h}$ and 


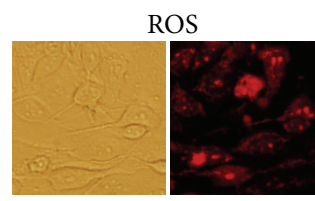

Control

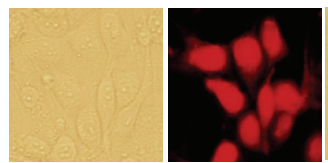

Model

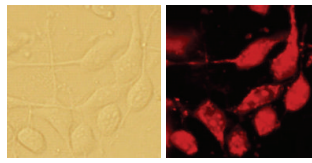

$\alpha$-Asarone

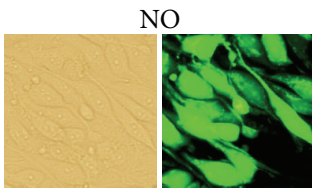

Control

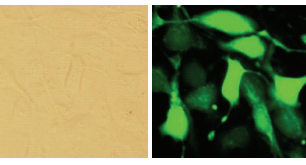

Model

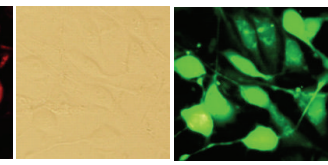

$\alpha$-Asarone

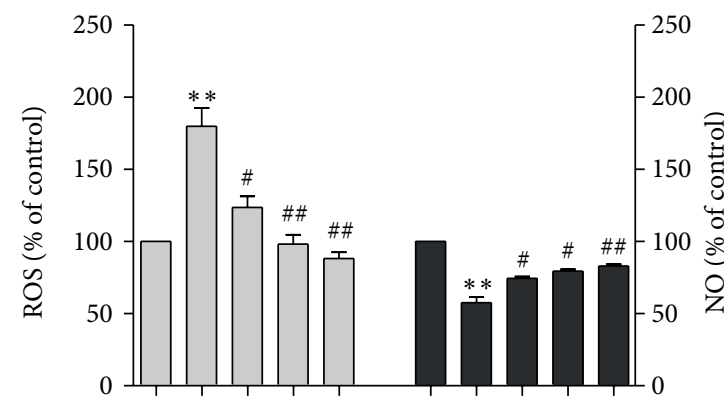

Ang II $-++++\quad+\quad+\quad++$ $\alpha$-A $10 \mu \mathrm{mol}-\quad+\quad+\quad+\quad-\quad-\quad+\quad+$

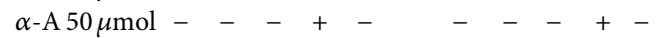
$\alpha$-A $100 \mu \mathrm{mol}-\quad-\quad-\quad+\quad-\quad-\quad-\quad+$

$\square$ ROS

$\mathrm{NO}$

(a)

(b)

FIGURE 2: Protection of $\alpha$-asarone against changes in ROS/NO levels in EA.hy926 cells induced by Ang II. Cells were treated with serum-free and phenol red-free RPMI 1640 medium (Control group) or Ang II (Model group) or pretreated with 10, 50 and $100 \mu$ mol/L of $\alpha$-asarone $(\alpha-\mathrm{A})$ for $1 \mathrm{~h}$, followed by Ang II at $0.1 \mu \mathrm{mol} / \mathrm{L}$ for $24 \mathrm{~h}$. The intracellular ROS and NO levels were detected with fluorescent dyes DHE and DAF-FM DA, respectively. Magnification, $\times 40$ (a). Data are expressed as means \pm SD from three independent experiments. ${ }^{* *} P<0.01$ versus control; ${ }^{\#} P<0.05$ versus model; ${ }^{\# \#} P<0.01$ versus model (b).

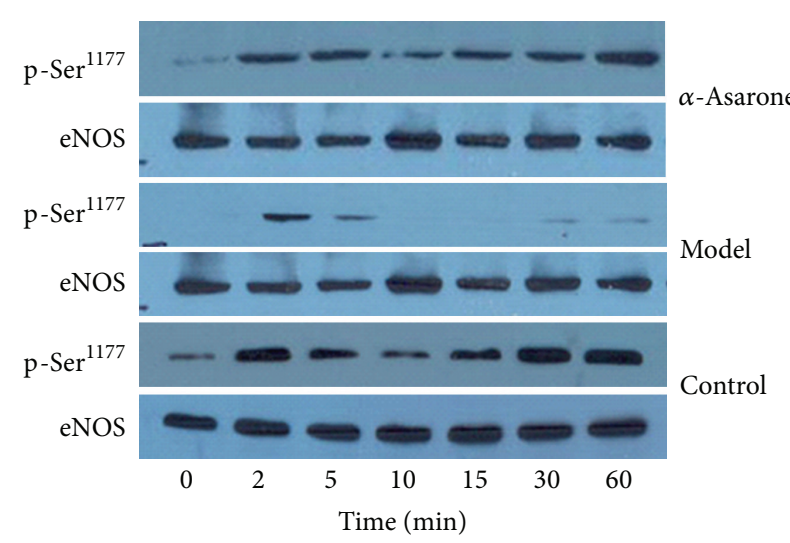

(a)

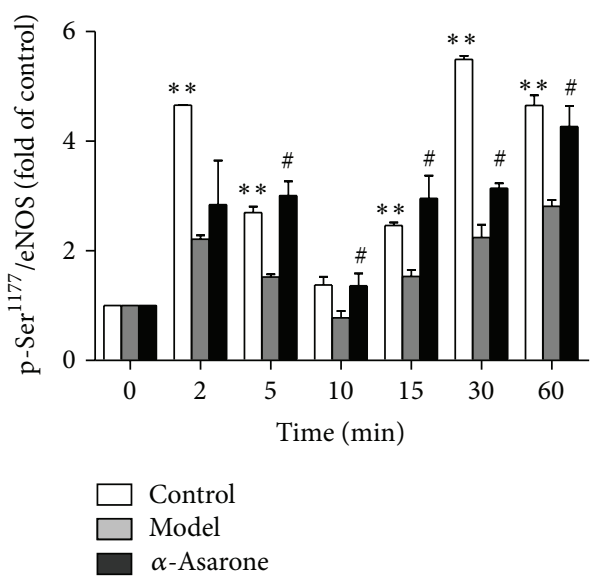

(b)

FIGURE 3: Protection of $\alpha$-asarone against Ang II-mediated impairment of the ACh-induced eNOS Ser ${ }^{1177}$ phosphorylation in EA.hy926 cells. Cells were stimulated either with ACh $(10 \mu \mathrm{mol} / \mathrm{L})$ only (a, Control), incubated with Ang II $(0.1 \mu \mathrm{mol} / \mathrm{L})$ for $24 \mathrm{~h}$, followed by stimulation with ACh (a, Model), or pr-treated with $\alpha$-asarone $(10 \mu \mathrm{mol} / \mathrm{L})$ for $1 \mathrm{~h}$ and then incubated with Ang II $(0.1 \mu \mathrm{mol} / \mathrm{L})$ for $24 \mathrm{~h}$, followed by stimulation with ACh (a, $\alpha$-asarone) for the indicated times. Cells were lysed and subjected to Western blot analysis of phosphorylated eNOS at $\operatorname{Ser}^{1177}$ or for total eNOS protein. Data are expressed as means \pm SD from three independent experiments. ${ }^{*} P<0.05 ;{ }^{* *} P<0.01$ versus 0 min group; ${ }^{\#} P<0.05$ versus model group (b).

stimulation with ACh $(10 \mu \mathrm{mol} / \mathrm{L})$ for $0-60 \mathrm{~min}$, the level of phosphorylated eNOS $\left(\operatorname{Ser}^{1177}\right)$ protein recovered to some extent over time and was close to that of the control group but significantly different in comparison with the model group $(P<0.05)$ (Figure 3, $\alpha$-asarone).

3.4. $\alpha$-Asarone at Concentrations up to $100 \mu \mathrm{mol} / \mathrm{L}$ Does Not Affect Proliferation of EA.hy 926 Cells. The effect of $\alpha$-asarone on proliferation of EA.hy926 cells was determined using the MTT method. After incubation with different concentrations of $\alpha$-asarone $(1 \sim 100 \mu \mathrm{mol} / \mathrm{L})$ for $24 \mathrm{~h}$, no significant difference in the proliferative capacity of EA.hy926 cells was observed among $\alpha$-asarone-treated and control groups (Figure 4). This result demonstrated that treatment with $\alpha$ asarone in this concentration range for $24 \mathrm{~h}$ had no effect on growth of EA.hy926 cells. 


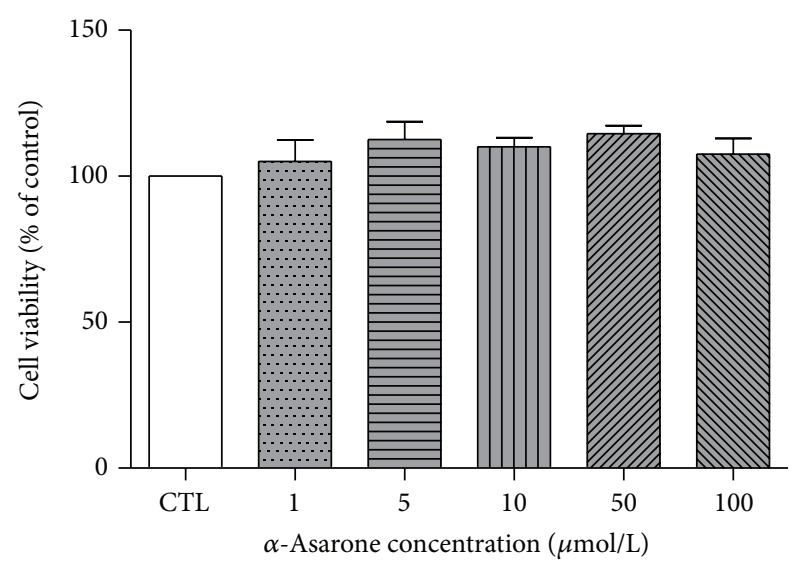

Figure 4: Viability of EA.hy926 cells treated with $\alpha$-asarone. Cells were treated with various concentrations of $\alpha$-asarone (1$100 \mu \mathrm{mol} / \mathrm{L}$ ) for $24 \mathrm{~h}$, and then cell viability was determined by the MTT assay. There was no significant difference between control (CTL) and $\alpha$-asarone treated groups. Data are expressed as means \pm SD from three independent experiments.

\section{Discussion}

The dysfunction of endothelial cells is the initiating factor and pathological basis of vascular lesions. As an important mediator of endothelial cell function, NO plays a key role in the maintenance of vascular homeostasis, and eNOS is the main enzyme driving the synthesis of endotheliumderived NO [18]. As eNOS is a constitutively expressed enzyme, its activity and function are mainly regulated by posttranslational modifications, acetylation, intracellular calcium concentration, phosphorylation, and S-nitrosylation. Various protein families and signaling pathways, including calmodulin $(\mathrm{CaM})$, caveolin-1, slow bradykinin B2 receptors, heat shock protein 90 (hsp90), and protein kinase B (PKB/Akt), are involved in the regulation of eNOS subcellular localization, catalytic function, and biological activity. The present study focused on the phosphorylation of eNOS as the primary posttranslational modification regulating its activity. The critical regulatory sites include Ser ${ }^{1177}, \operatorname{Ser}^{635}, \operatorname{Ser}^{617}$, $\mathrm{Thr}^{495}$, and Ser ${ }^{116}$, with eNOS activity being increased by phosphorylation at the former three sites and decreased by phosphorylation at the latter two sites [19]. In pathological conditions, the imbalance of the regulatory network will lead to the decrease of eNOS activity and consequently the decrease in NO production.

In a previous investigation in cultured bovine aortic endothelial cells, Ang II was found to increase $\mathrm{H}_{2} \mathrm{O}_{2}$ by activation of NADPH oxidase, causing the downregulation of intracellular dihydrofolate reductase (DHFR), decrease in $\mathrm{BH}_{4}$ levels, and uncoupling of eNOS, and ultimately leading to excess intracellular ROS and endothelial cell dysfunction [3]. In addition, Ang II and $\mathrm{H}_{2} \mathrm{O}_{2}$-mediated eNOS $\mathrm{Tyr}^{657}$ phosphorylation have been shown to inhibit eNOS activity and reduce NO production [5]. Ang II can also inhibit insulin-stimulated eNOS Ser ${ }^{177}$ phosphorylation and NO production, which may lead to the dysfunction of endothelial cells [4]. Furthermore, inhibition of large conductance calcium-activated potassium channels (BKCa) is one of the early responses, involving protein G, to Ang IImediated damage to vascular endothelial cells [19]. Ginkgo biloba extract, which can activate BKCa and defend against the adverse effects of Ang II on BKCa, has demonstrated protective effects on endothelial cells. In animal experiments, angiotensin receptor antagonists were confirmed to inhibit rat endothelial cell proliferation, migration, and matrix increase, and may improve endothelial cell function [20].

In this study, $\alpha$-asarone was investigated for its potential effect to preserve endothelial cells against Ang II-mediated damage. The results collectively suggest that $\alpha$-asarone dosedependently inhibited the Ang II-induced intracellular ROS with an $I_{\max }$ of $50.60 \pm 5.23 \%$. Meanwhile, the intracellular NO level was elevated with an $E_{\max }$ of $33.24 \pm 13.55 \%$. These results indicate that $\alpha$-asarone may improve Ang II-mediated eNOS uncoupling and provide antioxidant protection for endothelial cell function.

In addition, it has been reported that by inhibiting the phosphorylation of eNOS Ser ${ }^{1177}$, Ang II leads to the downregulation of eNOS activity and NO production, thereby causing endothelial cell dysfunction [4]. In the present study, a model of endothelial cell damage by Ang II was established via modulation of ACh-induced eNOS phosphorylation at $\operatorname{Ser}^{1177}$, and the protective effect of $\alpha$-asarone was investigated. In EA.hy926 endothelial cells stimulated with ACh $(10 \mu \mathrm{mol} / \mathrm{L})$ for different times $(0-60 \mathrm{~min})$, the phosphorylation of eNOS at $\operatorname{Ser}^{1177}$ was increased in a bimodal fashion. With the application of Ang II $(0.1 \mu \mathrm{mol} / \mathrm{L})$ to EA.hy926 cells for $24 \mathrm{~h}$ before treatment with ACh $(10 \mu \mathrm{mol} / \mathrm{L})$, eNOS Ser ${ }^{1177}$ phosphorylation disappeared over time, while total eNOS protein levels were unchanged. In order to investigate whether $\alpha$-asarone protected against Ang II-induced injury via eNOS Ser ${ }^{1177}$ phosphorylation, EA.hy926 cells were pretreated with $\alpha$-asarone $(10 \mu \mathrm{mol} / \mathrm{L})$ for $1 \mathrm{~h}$ before the $24 \mathrm{~h}$ incubation with Ang II and subsequent $1 \mathrm{~h}$ stimulation with ACh. Over a time course, the expression of phosphorylated eNOS $\left(\mathrm{Ser}^{1177}\right)$ recovered to a level which was close to that of the normal control group and significantly different compared with the model group. Drugs such as ACh classically mediated endothelium-dependent vasodilation by a mechanism of action that involves multiple intracellular signal transduction pathways, that is, (a) cholinergic receptors $(\mathrm{mAChR}) \rightarrow \mathrm{G}$ protein-coupled receptor (GPCR) $\rightarrow$ phospholipase C (PLC)-protein kinase A (PKA) $\rightarrow$ eNOS phosphorylation; (b) GPCRs $\rightarrow$ Tyr K (Tyrosine Kinase, Tyr K) $\rightarrow$ PI3K/Akt $\rightarrow$ eNOS phosphorylation; and (c) GPCRs $\rightarrow$ IR (insulin receptor, IR) $\rightarrow$ IP 3K/Akt $\rightarrow$ eNOS phosphorylation. As observed in the current study, ACh treatment induced eNOS Ser ${ }^{177}$ phosphorylation in EA.hy926 endothelial cells within a short period of time (1h). Therefore, ACh was an efficient tool for examining the efficacy of $\alpha$-asarone against Ang II-mediated inhibition of eNOS activation. Incubation of the EA.hy926 cells with Ang II for $24 \mathrm{~h}$ significantly lowered the ACh-induced eNOS Ser ${ }^{177}$ phosphorylation, suggesting that Ang II may exert endothelial cell damage through this pathway. Meanwhile, 
pretreatment with $\alpha$-asarone obviously improved the Ang II-mediated inhibition of eNOS Ser ${ }^{1177}$ phosphorylation by $\mathrm{ACh}$, suggesting that $\alpha$-asarone may play a role in protecting endothelial cell function through preserving the pathway to activation of eNOS. Whether $\alpha$-asarone acts synergistically with ACh or by other means to regulate eNOS activity, as the mechanism of protection against Ang II-induced endothelial cell dysfunction, remains to be further explored.

As it has been previously reported in animal experiments and cultured liver cells that long-term treatment with high concentrations of $\alpha$-asarone results in toxicity to liver and reproductive tissues [21-23], the MTT assay was used here to test the effect of a $24 \mathrm{~h}$ incubation with $\alpha$-asarone (1$100 \mu \mathrm{mol} / \mathrm{L}$ ) on proliferation of EA.hy926 cells. The proliferation of EA.hy926 cells treated with $\alpha$-asarone was not significantly different from that of the control, suggested that concentrations up to $100 \mu \mathrm{mol} / \mathrm{L}$ of $\alpha$-asarone are safe for these cells.

Although $\alpha$-asarone protected endothelial cells by restored eNOS $\operatorname{ser}^{1177}$ phosphorylation, the mechanism remains to be further studied. Tissue factor (TF) and plasminogen activator inhibitor-1 (PAI-1) were markers of the endothelial cells injury [24]. It was reported that Ang II induced the expression of tissue TF and PAI-1 in vascular endothelial cells [25]. Thus, we will further investigate the effects of $\alpha$-asarone on TF or PAI- 1 in the future.

A previous study reported that $\alpha$-asarone inhibited lipid synthesis and secretion in long-term cultures of adult rat hepatocytes [15]. The neuroprotective effect of $\alpha$-asarone on spatial memory and nitric oxide levels in rats was investigated in recent study [12]. The endothelium-dependent vasodilatory effect of $\alpha$-asarone was studied in this study and we found that $\alpha$-asarone could protect EA.hy926 cells against Ang II-induced injury. However, it is unclear whether $\alpha$ asarone only acts on endothelial cells. We will use different endothelial cell lines to further clarify the effects of $\alpha$-asarone in future studies.

\section{Conclusion}

This study showed that $\alpha$-asarone could protect EA.hy926 cells against injury induced by Ang II, possibly attributed to its antioxidant activity and by modulating eNOS phosphorylation. Further studies are clearly needed to reveal the regulatory effect of $\alpha$-asarone on the other phosphorylated sites in Ang II-induced endothelial cells.

\section{Conflict of Interests}

The authors have declared that there is no conflict of interests.

\section{Acknowledgments}

This work was supported in part by Grants from the Ministry of Education of China [05ZZ11], Shanghai Municipality Government [05JC14056], and the National Science and Technology Major Project of China [2009ZX09311-003]. The authors thank their colleagues and the laboratory staff of the Murad Research Center for Modernization Chinese Medicine, Shanghai University of Traditional Chinese Medicine, for their assistance. They also acknowledge the support of Ning Tang and Xiao-Dong Hua for providing materials.

\section{References}

[1] K. Bian and F. Murad, "Nitric oxide signaling in vascular biology," Journal of the American Society of Hypertension, vol. 1, no. 1, pp. 17-29, 2007.

[2] S. Higuchi, H. Ohtsu, H. Suzuki, H. Shirai, G. D. Frank, and S. Eguchi, "Angiotensin II signal transduction through the AT1 receptor: novel insights into mechanisms and pathophysiology," Clinical Science, vol. 112, no. 8, pp. 417-428, 2007.

[3] K. Chalupsky and H. Cai, "Endothelial dihydrofolate reductase: critical for nitric oxide bioavailability and role in angiotensin II uncoupling of endothelial nitric oxide synthase," Proceedings of the National Academy of Sciences of the United States of America, vol. 102, no. 25, pp. 9056-9061, 2005.

[4] J. C. Zhong, D. L. Zhu, X. Y. Yu, H. M. Yu, and M. Zhou, "Effects of recombinant ACE2 gene on eNOS phosphorylation levels in human vascular endothelial cells," Space Medicine \& Medical Engineering, vol. 22, no. 3, pp. 172-175, 2009.

[5] A. E. Loot, J. G. Schreiber, B. Fisslthaler, and I. Fleming, "Angiotensin II impairs endothelial function via tyrosine phosphorylation of the endothelial nitric oxide synthase," The Journal of Experimental Medicine, vol. 206, no. 13, pp. 28892896, 2009.

[6] L. Li, Y. Y. Zou, C. Shi, G. Wei, S. F. Lin, and Y. Q. Fang, "Comparative investigation on the drug effect of beta-asarone, alpha-asarone and volatile oil of Acorus tatarinowii schott on bronchial asthma," Lishizhen Medicine and Materia Medica Research, vol. 17, no. 11, pp. 2137-2138, 2006.

[7] W.-P. Liao, L. Chen, Y.-H. Yi et al., "Study of antiepileptic effect of extracts from Acorus tatarinowii schott," Epilepsia, vol. 46, no. 1, supplement, pp. 21-24, 2005.

[8] Y. Z. Chen, R. M. Fang, G. Wei et al., "Effect of volatile oil of acorus and $\beta$-asarone on vasomotion and anti-platelet aggregation in rats with hyperlipidemia," Chinese Journal of Integrated Traditional and Western Medicine, vol. 24, no. 1, supplemment, p. 3, 2004.

[9] Q. D. Wu, Y. Q. Fang, Y. Z. Chen, Z. S. Kuang, S. Y. Wang, and Y. P. He, "Protective effects of volatile oil of Acorus tatarinowii schott and beta-asarone on cardiovascular system," Traditional Chinese Drug Research \& Clinical Pharmacology, vol. 16, no. 4, pp. 244-247, 2005.

[10] Q. Z. Lin, "Study of active fraction of Acorus tatarinowii schott on lipid-lowering," Chinese Herbal Medicine, vol. 13, pp. 3-4, 1982.

[11] J. Cho, Y. H. Kim, J.-Y. Kong, C. H. Yang, and C. G. Park, "Protection of cultured rat cortical neurons from excitotoxicity by asarone, a major essential oil component in the rhizomes of Acorus gramineus," Life Sciences, vol. 71, no. 5, pp. 591-599, 2002.

[12] I. D. Limón, L. Mendieta, A. Díaz et al., "Neuroprotective effect of alpha-asarone on spatial memory and nitric oxide levels in rats injected with amyloid- $\beta(25-35)$," Neuroscience Letters, vol. 453, no. 2, pp. 98-103, 2009.

[13] P. C. Dandiya and M. K. Menon, "Effects of asarone and betaasarone on conditioned responses, fighting behaviour and convulsions," British Journal of Pharmacology and Chemotherapy, vol. 20, no. 1, pp. 436-442, 1963. 
[14] N. Pages, P. Maurois, B. Delplanque et al., "Activities of $\alpha$ asarone in various animal seizure models and in biochemical assays might be essentially accounted for by antioxidant properties," Neuroscience Research, vol. 68, no. 4, pp. 337-344, 2010.

[15] A. Hernandez, M. L. Lopez, G. Chamorro, and T. MendozaFigueroa, "Inhibition of lipid synthesis and secretion in longterm cultures of adult rat hepatocyes by $\alpha$-asarone," Planta Medica, vol. 59, no. 2, pp. 121-124, 1993.

[16] S. H. Lee, K.-Y. Kim, S. Y. Ryu et al., "Asarone inhibits adipogenesis and stimulates lipolysis in 3T3-L1 adipocytes," Cellular and Molecular Biology, vol. 56, no. 1, supplement, pp. 1215-1222, 2010.

[17] J. Poplawski, B. Lozowicka, A. T. Dubis et al., "Synthesis and hypolipidemic and antiplatelet activities of $\alpha$-asarone isomers in humans (in vitro), mice (in vivo), and rats (in vivo)," Journal of Medicinal Chemistry, vol. 43, no. 20, pp. 3671-3676, 2000.

[18] D. M. Dudzinski and T. Michel, "Life history of eNOS: partners and pathways," Cardiovascular Research, vol. 75, no. 2, pp. 247260, 2007.

[19] L. Lin, Y. F. Zheng, J. H. Qu, and G. H. Bao, "The cellular mechanism of angiotensin II inhibition on BKCa of ECV304 cell and the protective effect of gingko leaf extract," Acta Academiae Medicinae Sinicae, vol. 23, no. 5, pp. 467-471, 2001.

[20] L. Iouzalen, O. Stepien, and P. Marche, "Effects of bay 10-6734 (Embusartan), a new angiotensin II type I receptor antagonist, on vascular smooth muscle cell growth," The Journal of Pharmacology and Experimental Therapeutics, vol. 289, no. 1, pp. 181-187, 1999.

[21] M. L. Lopez, A. Hernandez, G. Chamorro, and T. MendozaFigueroa, " $\alpha$-asarone toxicity in long-term cultures of adult rat hepatocytes," Planta Medica, vol. 59, no. 2, pp. 115-120, 1993.

[22] G. Chamorro, L. Garduño, E. Martínez, E. Madrigal, J. Tamariz, and M. Salazar, "Dominant lethal study of $\alpha$-asarone in male mice," Toxicology Letters, vol. 99, no. 2, pp. 71-77, 1998.

[23] G. Chamorro, M. Salazar, J. Tamariz, F. Diaz, and F. Labarrios, "Dominant lethal study of alpha-asarone in male and female mice after sub-chronic treatment," Phytotherapy Research, vol. 13, no. 4, pp. 308-311, 1999.

[24] A. S. Gram, J. Skov, P. Thorkil, J. J. Sidelmann, B. M. Stallknecht, and E. M. Bladbjerg, "Biomarkers of coagulation, fibrinolysis, endothelial function, and inflammation in arterialized venous blood," Blood Coagulation \& Fibrinolysis, 2014.

[25] H. Nishimura, H. Tsuji, H. Masuda et al., "Angiotensin II increases plasminogen activator inhibitor-1 and tissue factor mRNA expression without changing that of tissue type plasminogen activator or tissue factor pathway inhibitor in cultured rat aortic endothelial cells," Thrombosis and Haemostasis, vol. 77, no. 6, pp. 1189-1195, 1997. 


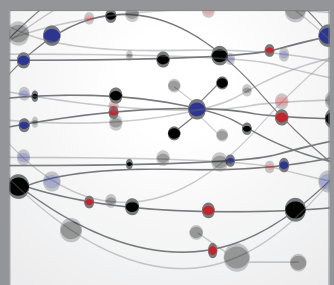

The Scientific World Journal
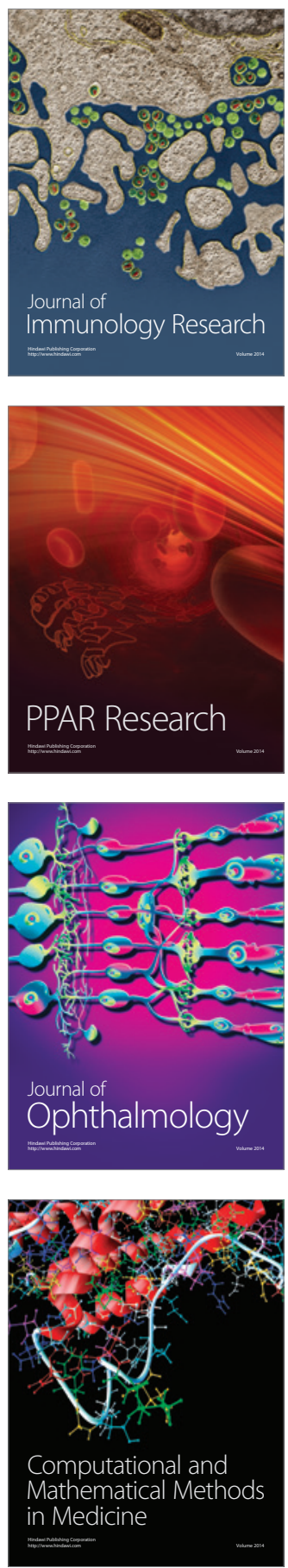

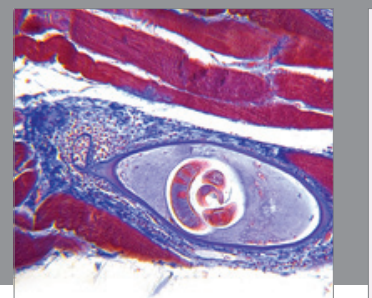

Gastroenterology

Research and Practice
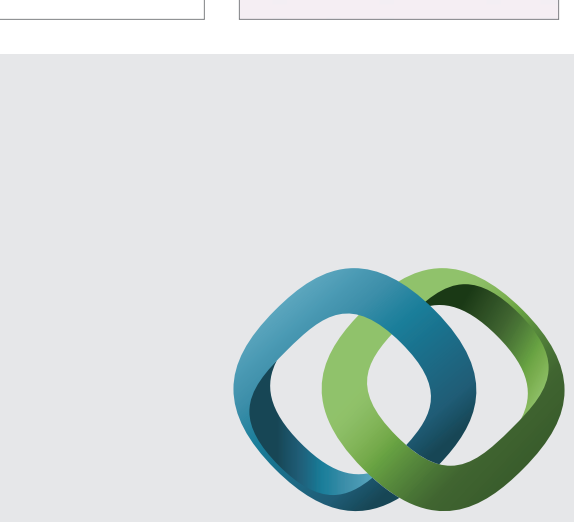

\section{Hindawi}

Submit your manuscripts at

http://www.hindawi.com
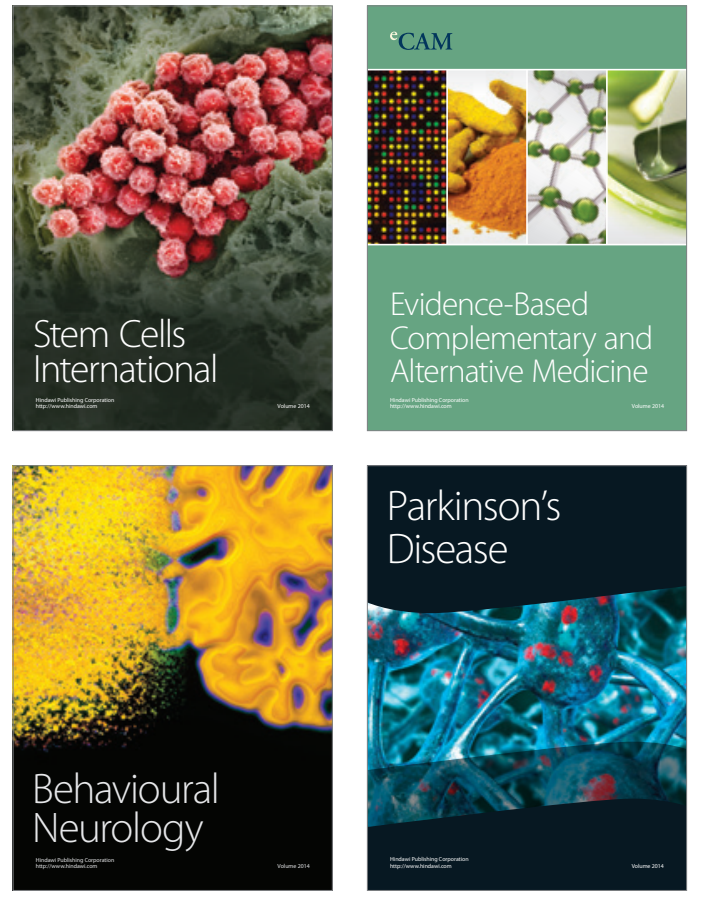
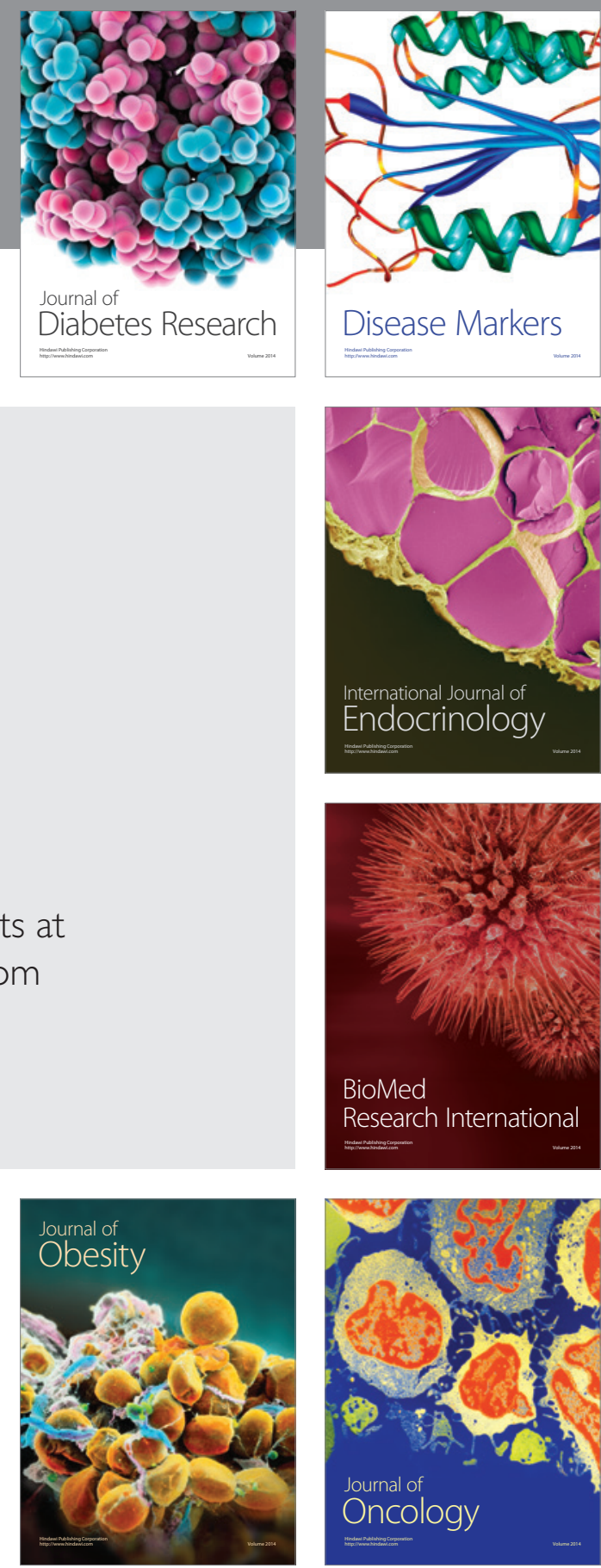

Disease Markers
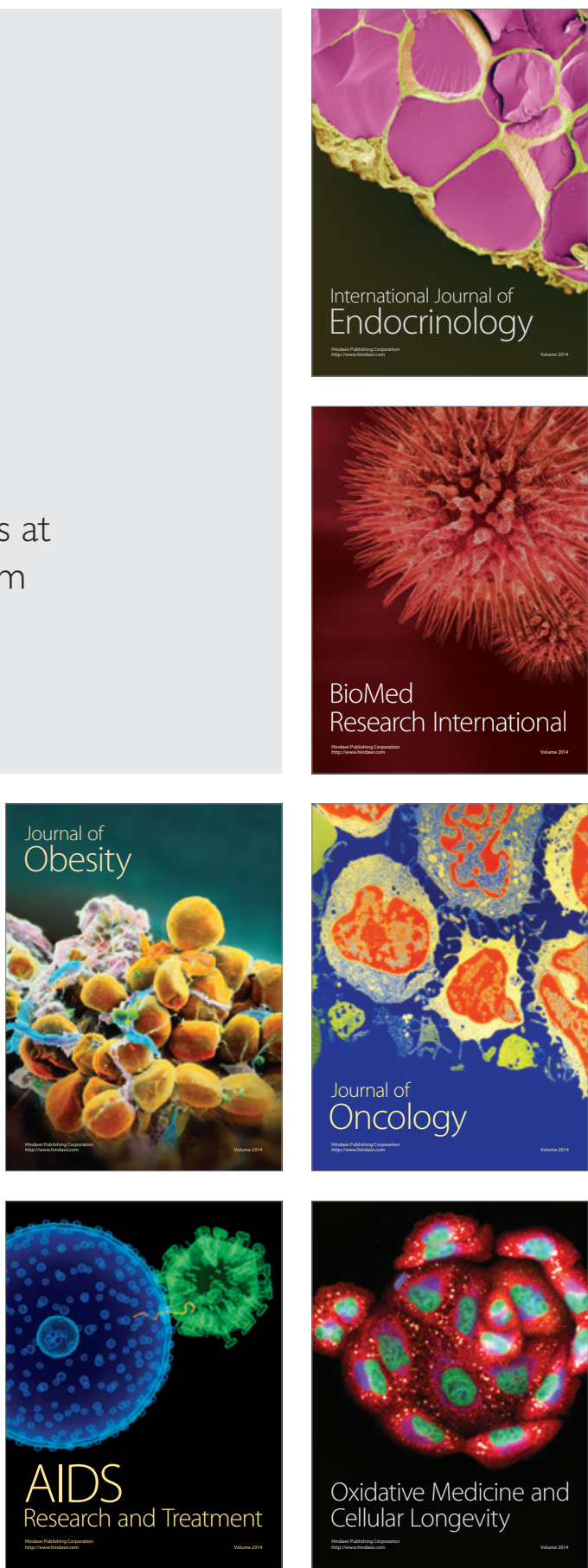